\title{
SILICOSIS WITH PROGRESSIVE MASSIVE FIBROSIS: A CASE REPORT
}

\author{
Anjali', Anuranjan Dubey², Gyanendra Narayan Singh ${ }^{3}$, Anjali Verma 4 , Vijay Shankar Prasad ${ }^{5}$
}

${ }_{1}^{1}$ Postgraduate Resident, Department of Radiodiagnosis, Patna Medical College and Hospital, Patna.

2Postgraduate Resident, Department of Orthopaedics, Patna Medical College and Hospital, Patna.

3 Professor and HOD, Department of Radiodiagnosis, Patna Medical College and Hospital, Patna.

${ }^{4}$ Assistant Professor, Department of Physiology, Patna Medical College and Hospital, Patna.

5 Professor, Department of Radiodiagnosis, Patna Medical College and Hospital, Patna.

\section{ABSTRACT}

Progressive massive fibrosis characterised by the development of large conglomerate masses of dense fibrosis usually in the upper lung zones can complicate silicosis and coal worker's pneumoconiosis.(1-3) The disease initiates through deposition of silica and coal in the lung and then by body's immunological reaction to the dust. Here, we present a case report of a 55-year-old man who presented to our emergency department with gradually progressive dyspnoea.

\section{KEYWORDS}

Progressive Massive Fibrosis (PMF), HRCT (High Resolution Computed Tomography).

HOW TO CITE THIS ARTICLE: Anjali, Dubey A, Singh GN, et al. Silicosis with progressive massive fibrosis: a case report. J. Evolution Med. Dent. Sci. 2016;5(65):4676-4677, DOI: 10.14260/jemds/2016/1065

\section{INTRODUCTION}

Pneumoconiosis is caused by accumulation of inhaled particulates and involves the reaction of tissue in the lung. Silicosis is one of the common forms of pneumoconiosis caused by inhalation of particles of crystalline silicon dioxide. Occupations such as mining, quarrying are associated with it.(4-8)

Cases of silicosis maybe classified as simple or complicated according to the radiographic findings.

In the simple form, there are multiple small nodules $2-5$ $\mathrm{mm}$ in diameter accompanied by calcification. They tend to be most common in upper lobes of lungs.

Complicated silicosis also known as progressive massive fibrosis develops through the expansion and confluence of individual silicotic nodules. Chest radiographs and CT scan show bilateral symmetrical large opacities with irregular or illdefined margins and calcifications surrounded by emphysematous changes. The lateral interface of the mass typically parallels the lateral chest wall.

Hilar and mediastinal lymph nodal enlargement may precede the development of parenchymal nodular lesions. Calcification of the lymph node is common and typically occurs at the periphery of the node, the egg shell pattern, which is highly suggestive of silicosis.(9) A criteria has been published for diagnosing the egg shell pattern of calcification:(10-11)

- Shell-like calcification up to $2 \mathrm{~mm}$ thick must be present in the peripheral zone of atleast two lymph nodes.

- The calcifications maybe solid or broken.

- In atleast one of the lymph nodes, the ring-like shadow must be complete.

- The central part of lymph nodes may show additional calcifications.

- One of the affected lymph nodes must be at least $1 \mathrm{~cm}$ in its greatest diameter.

Financial or Other, Competing Interest: None.

Submission 08-07-2016, Peer Review 01-08-2016,

Acceptance 07-08-2016, Published 14-08-2016.

Corresponding Author:

Dr. Anjali,

Room No. 36,

Kasturba P.G. Girls Hostel,

Patna Medical College and Hospital,

Patna - 800004

E-mail: ianjalipmch@gmail.com

DOI: $10.14260 /$ jemds/2016/1065

\section{CASE DESCRIPTION}

A 55-year-old man presented to the emergency department with the complaint of progressive worsening of dyspnoea over 4 weeks. He had no constitutional symptoms, fever, or expectoration. He had no other major illness or associated comorbidity. He was a nonsmoker. Occupational history revealed he had been working in a silica mining factory since 25 years.

Routine investigations and laboratory tests were performed, which were within normal limits.

Pulmonary function tests revealed moderate restriction and reduced diffusing capacity. HRCT thorax was done.

IMAGING FINDINGS The scanogram shows bilateral symmetrical mass-like opacities with areas of calcification within.

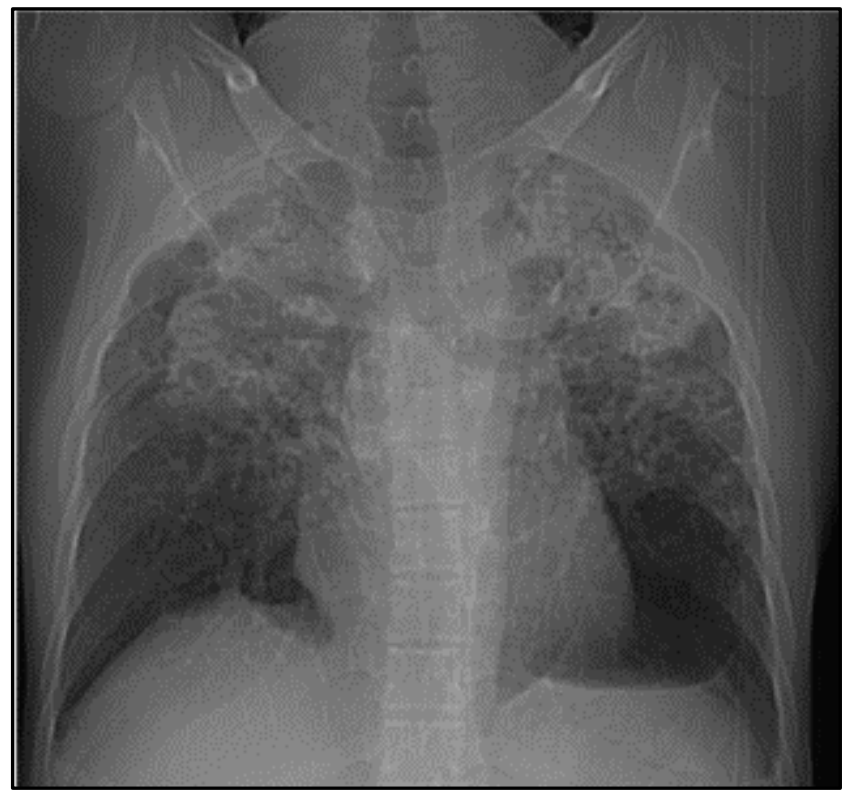

Fig. 1: Scanogram Showing Bilateral Upper Zone Opacities

Lung and mediastinal window images showed conglomerate sausage shaped bilateral masses with calcification, surrounding reticulations, and fibrosis predominantly involving the upper lobes of lungs. 
There were areas of compensatory emphysema in the unaffected portion between masses and pleura. Multiple variable-sized calcified hilar and mediastinal lymph nodes were evident, few of them with characteristic peripheral 'eggshell' type of calcification.

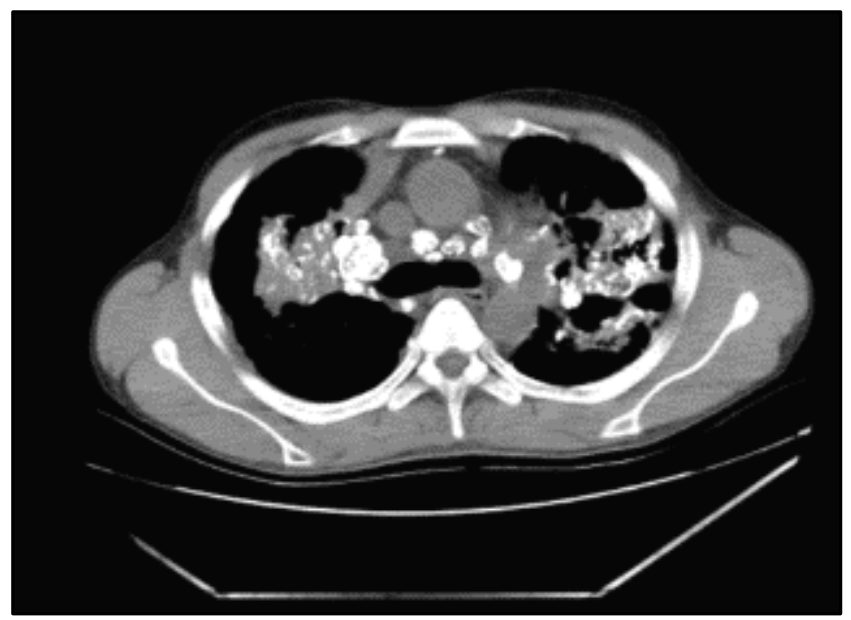

Fig. 2: HRCT Lung (Mediastinal Window) Shows Characteristic Eggshell Hilar Node Calcification

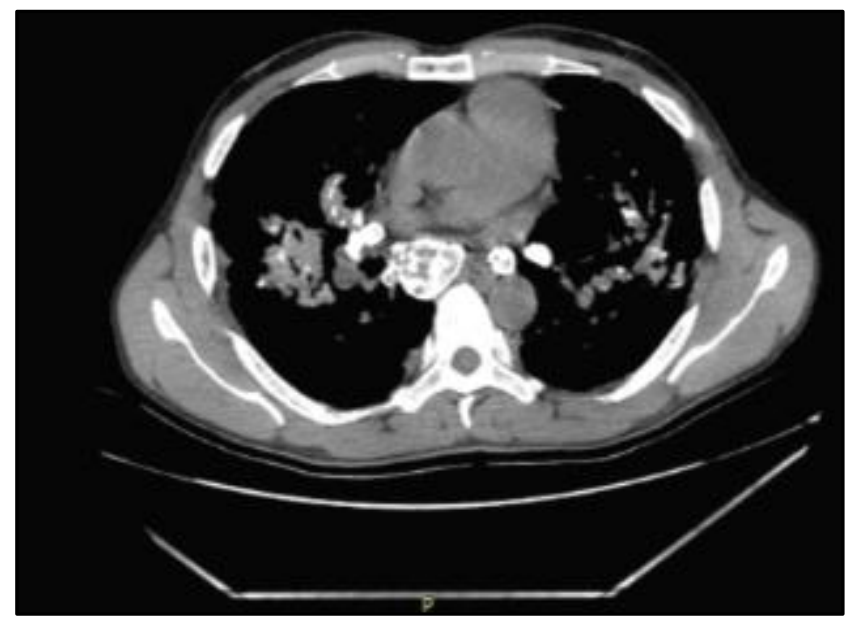

Fig. 3: HRCT Lung Shows bilateral Calcified Masses in Lung With Calcified Nodes

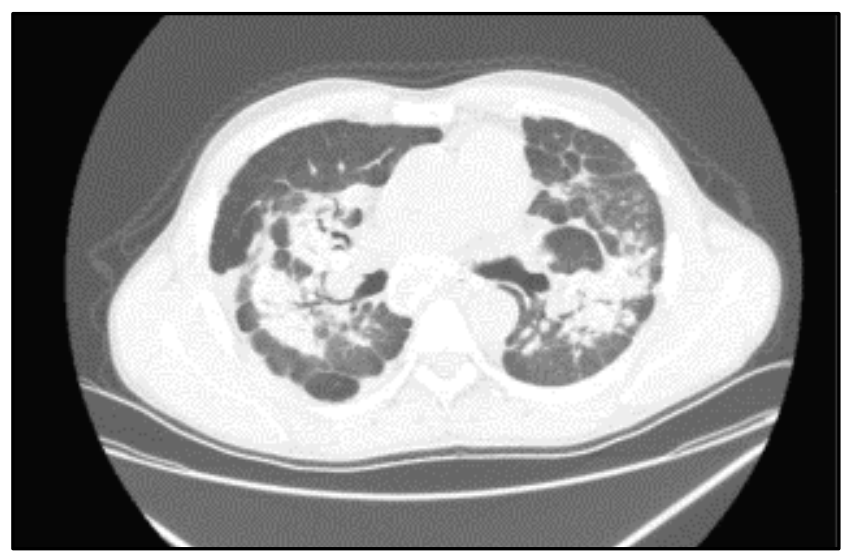

Fig. 4: HRCT Lung Shows Bilateral Conglomerate Fibrotic Masses Bordered by Emphysematous Areas

In the light of patient's occupation, his clinical presentation and findings on imaging a diagnosis of progressive massive fibrosis also known as complicated silicosis was made.

\section{DISCUSSION AND CONCLUSION}

Silicosis is a form of pneumoconiosis, which can manifest as progressive massive fibrosis, a complicated form. Carcinoma and tuberculosis are two potential complications of silicosis. High-resolution CT demonstrates the characteristic distribution and findings of the disease and associated complications. The diagnosis should be made by integrating the history of occupational exposure to inorganic dusts or fumes with imaging findings.

\section{REFERENCES}

1. Jacobson G, Felson B, Pendergrass EP, et al. Eggshell calcification in coal and metal miners. Semin Roentgenol 1967;2(3):276-82.

2. Chong S, Lee KS, Chung MJ, et al. Pneumoconiosis: comparison of imaging and pathologic findings. Radiographics RSNA 2006;26(1):59-77.

3. Oikonomou A, Muller NL. Imaging of pneumoconiosis. Imaging 2003;15(1):11-22.

4. Fujimura N. Pathology and pathophysiology of pneumoconiosis. Curr Opin Pulm Med 2000;6(2):140-4.

5. Marchiori E, Ferriera A, Muller NL. Silicoproteinosis: highresolution CT and histologic findings. J Thorac Imaging 2001;16(2):127-129.

6. Akira M. High-resolution CT in the evaluation of occupational and environmental diseases. Radiol Clin North Am 2002;40(1):43-59.

7. Feigin DS. Talc: understanding its manifestations in the chest. Am J Roentgenol 1986;146(2):295-301.

8. Remy-Jardin M, Degreef JM, Beuscart R, et al. Coal worker's pneumoconiosis: CT assessment in exposed workers and correlation with radiographic findings. Radiology 1990;177(2):363-71.

9. Dee $P$, Suratt $P$, Winn $W$. The radiographic findings in acute silicosis. Radiology 1978;126(2):359-63.

10. Weil I, Jones R, Parkes W. Silicosis and related diseases. In: Parkes W. ed. Occupational lung disorders. $3^{\text {rd }}$ edn London, England: Butterworths 1994:285-339.

11. McLoud TC. Occupational lung disease. Radiol Clin North Am 1991;29(5):931-41. 